\title{
Interruption of Chagas Disease Transmission in the Andean Countries: Colombia
}

\author{
Felipe Guhl ${ }^{+}$, Gustavo A Vallejo*
}

Centro de Investigaciones en Microbiología y Parasitología Tropical, Universidad de los Andes, Apartado Aéreo 4976, Santafé de Bogotá, Colombia *Departamento de Biología, Facultad de Ciencias, Universidad del Tolima, Apartado Aéreo 465, Ibagué, Colombia

Key words: control - Chagas disease - Trypanosoma cruzi - triatomines

From a total population of 360 million people living in areas endemic for Chagas disease, it is estimated that at least 100 million are exposed to the risk of infection, and that 16 to 18 million are currently infected with the causative agent, Trypanosoma cruzi. According to estimates in 1991 by the World Health Organization, approximately 500,000 people become infected each year in the absence of control programmes, and 300,000 out of this number are children. The mortality rate can reach 5 to $15 \%$ during the initial acute phase of the infection.

In Colombia, the first case of Chagas disease was reported in 1929. Since then, numerous studies have contributed to our epidemiological knowledge (Marinkelle 1975), and it is now estimated that there are 1,3 million infected people in the country, with a further 3,6 million people considered at risk since they live in regions known to harbour the domestic insect vectors. Fig. 1 shows the vectorial transmission areas in Colombia, with estimates of their different risk levels.

Twenty species of triatomine vectors have been reported in Colombia. The most important in epidemiological terms are those that live in close association with humans, living in cracks and crevices of rural dwellings and emerging at night to suck the blood of the sleeping occupants. Rhodnius prolixus, is the main domestic vector in Colombia, followed in importance by Triatoma dimidata and T. maculata. Other species such as $R$. robustus, $R$. brethesi, R. pallescens and T. venosa are generally silvatic in habit, rarely coming in contact with humans and so of lesser epidemiological significance (D'Alessandro et al. 1981). The importance of each species as a vector of T. cruzi depends on several

\footnotetext{
${ }^{+}$Corresponding author. Fax: $+571-286.7593$. E-mail: fguhl@uriandes.edu.co

Received 9 June 1999

Accepted 9 August 1999
}

factors, such as geographical distribution, density of domestic or peridomestic populations, preference for feeding on humans or other domestic vertebrates, feeding frequency, susceptibility to the infection, and capacity to produce the infective metacyclic trypomastigote forms of $T$. cruzi. All these factors, taken as a whole, are important for the implementation of vector control programmes and epidemiological surveillance of Chagas disease transmission.

The insect vectors probably account for over 90\% of transmission of T.cruzi to humans, but transmission can also occur via blood transfusion from infected donors. This is also important in Colombia where an average of 450,000 bloodunits/year are used, and the prevalence of the infection in blood donors ranges from an average of $3.3 \%$ in endemic areas, to $1.3 \%$ in non-endemic areas.

\section{CONTROL ACTIVITIES}

Until the 1980s, the real scale of the Chagas disease problem in Colombia was unknown, and there was no national policy concerning the disease. Control activities were very sporadic, although small scale control trials with different insecticides were carried out in highly endemic regions, and limited serological surveys were undertaken.

It was only in 1990 that the results of a national entomological survey became known (Corredor et al. 1990), and in 1995 data were published to show the national prevalence of infection in blood donors in the country (Guhl et al. 1995). These reports represented major steps in medical surveillance, laying the basis for current control activities. Thus in 1995 the Ministry of Health established a mandatory law for serological screening in blood donors, and in 1996 set up a national programme for vector control transmission of Chagas disease with pilot control programmes set up in several of the most endemic areas of the country. 


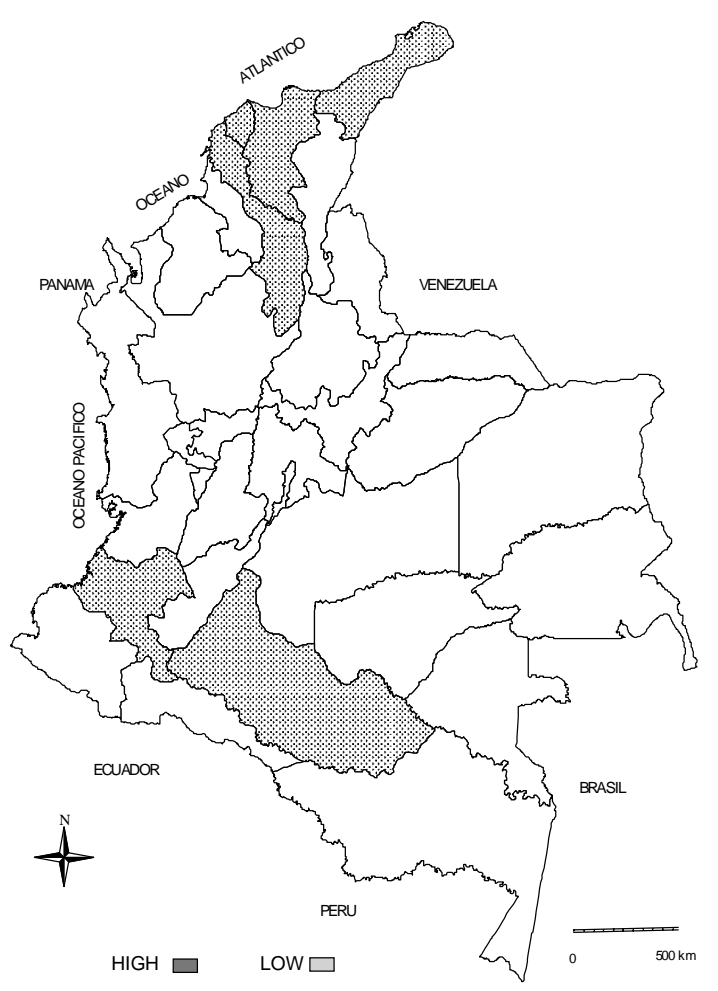

Fig. 1: risk areas of vectorial transmission in Colombia.

In February 1997, the Andean Countries Initiative for Vectorial Control of Chagas Disease was launched, sponsored by the Ministry of Health and the World Health Organization. Invited by the Colombian Ministry of Health, delegates from Venezuela, Ecuador, Perú, Bolivia and Chile met in Bogotá. Based on technical and experimental data from the different countries and the preparation of draft national plans of action, the delegates considered it was feasible to launch a multinational programme to halt the transmission of Chagas disease, primarily by eliminating the domestic insect vectors and controlling the national blood transfusion systems.

To comply with the international commitment, Colombia started in 1998 the National Program of Prevention and Control of Chagas Disease and Children's Cardiopathy in nine departments (covering $45 \%$ of the country's endemic area).

\section{STRATEGIES}

From the results of pilot studies in endemic areas of Cundinamarca and Santander, the guidelines of the exploratory phase of the National Program were extracted. This phase involves geographical stratification of the epidemiological status of $T$. cruzi infection, so that control measures can be applied in an efficient and adequate way.
The risk areas are being identified so that later in 1999, appropriate control measures will be implemented in areas of most risk. To establish the control program, maps showing the various epidemiological factors involved are being prepared using geographical information systems (GIS). The Andean Countries Initiative has generated simultaneously the need for research on distribution, dynamics and genetic structure of non-domiciliary populations of triatominae. The study of the interaction between silvatic, peridomestic and domestic vector populations is essential in order to collect enough entomological data for control strategies and programs (Dujardin et al. 1997). Triatominae populations in Colombia show a high level of diversity and are widely distributed in wild cycles. The domiciliation process of these species must be studied and understood as a complement to entomological surveillance and future control strategies (Guhl \& Schofield 1996).

In contrast to the broad genetic variability suggested by isoenzyme (zymodeme) analysis, $T$. cruzi populations have been characterized recently into two lineages, based on the observed dimorphism of sequences of gene $24 \alpha$ rRNA and the non-transcriber spacer of the mini-exon gene (Zingales et al.1998). These authors have demonstrated a strong link between linage 1 and the domestic transmission cycle (previously referred to as zymodeme group Z2) and between linage 2 and the wild transmission cycle (previously referred to as zymodeme group Z1). This situation has also been observed in Colombia.

The presence of $T$. rangeli in the countries of Central America and the northern part of South America introduces added complexity to surveillance for T. cruzi. In recent studies, two lineages of T. rangeli associated to domestic transmission cycles (KP1+) and wild transmission cycles (KP1-) have been discriminated using primers designed on kDNA mini-circles in a duplex PCR (Vallejo et al. 1997). Fig. 2 shows the discriminative pattern between two sub-populations of $T$. rangeli $(\mathrm{KP} 1+)$ and (KP1-) by using the primers S35, S36 and KP1L that anneal around kDNA mini-circles. The relative proportion of these sub-populations in domestic and wild cycles is different, reflecting a larger flow of parasites from silvatic to domestic cycles. This may provide an additional marker for monitoring domestic invasion by silvatic species of Triatominae, and the presumed interaction of these sub-populations on the vectors as well as on vertebrate hosts holds a particular interest.

In recent studies, $T$. cruzi and $T$. rangeli subpopulations have been detected in domestic $R$. prolixus in Colombia, and in some cases the same individual insect may be infected by both. This is 


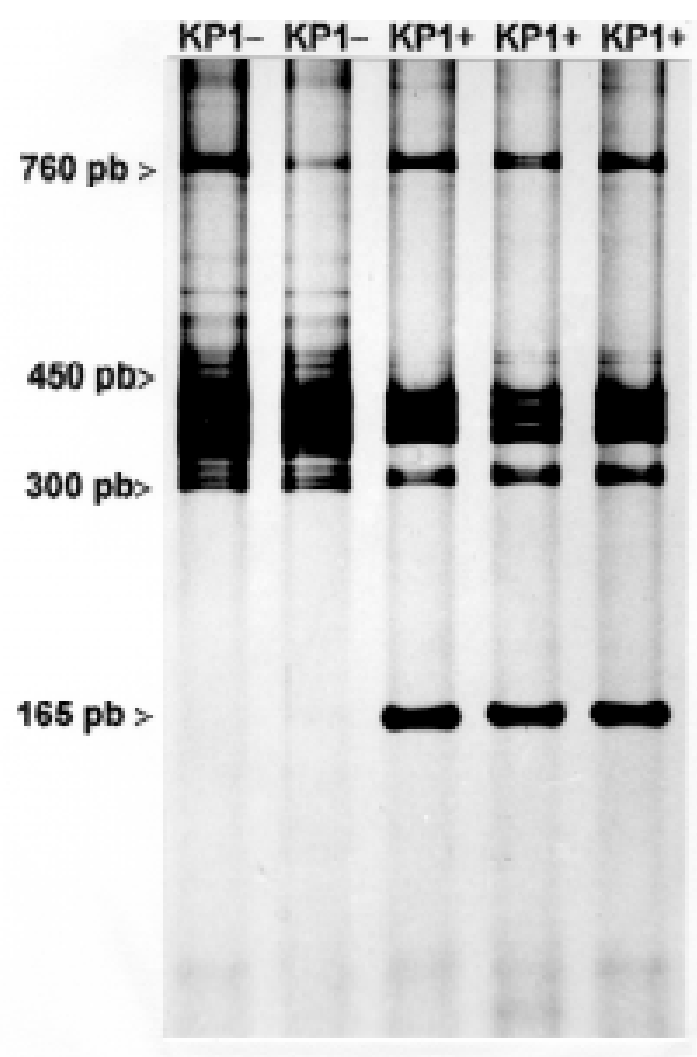

Fig. 2: polyacrilamide gel (6\%) colored with silver nitrate, showing the Trypanosoma rangel $\mathrm{kDNA}$ amplified profiles, in a PCR duplex reaction, with S35, S36 and KP1L primers. The amplification profile of strains (KP1-) isolated from wild cycles and of strains (KP1+) isolated from domestic cycles, shows only one difference: a band of $165 \mathrm{pb}$ derived from a kDNA minicircle of $1764 \mathrm{pb}$, known as KP1 and present only in domestic strains .

substantially different from the epidemiology of $T$. cruzi in the Southern Cone countries, where $T$. rangeli has only rarely been recorded. It may be that interactions between different parasite subpopulations would help to explain the variability of clinical manifestations of Chagas disease in Latin America.

The methods applied in the Chagas disease control programme must satisfy local needs in terms of efficacy, economy, and social acceptance. It is also necessary that the strategy is flexible enough to respond to new techniques and the economic changes. Development of the descentralization law for municipalities, with its intersectoral and interinstitutional approach, led to the inclusion within the Chagas disease vector control strategies of the improvement of dwellings and the con- cept "good dwelling, healthy family". Similarly, the Ministry of Health and research centres with experience in different aspects of Chagas disease have promoted and taught regular courses and training workshops at a national level.

\section{RESULTS}

Since the creation of the National Program of Control in 1996, approximately 20,000 dwellings have been sprayed with modern pyrethroid insecticides in order to eliminate domestic Triatominae, and 510 dwellings have been enrolled in the housing improvement programme.

\section{PERSPECTIVES}

The immediate objectives and tasks for the 1999 involve expansion of activities to cover the remaining areas of vectorial transmission, so that they may be appropriately included within the National Program. In addition, it is considered of priority to design and implement treatment protocol and followup of Chagas disease patients.

\section{REFERENCES}

Corredor A, Santacruz M, Paez S y Guatame L 1990. Distribución de los Triatominos Domiciliarios en Colombia,Instituto Nacional de Salud, Bogotá, 144 pp.

D’Alessandro A, Barreto MP, Thomas M 1981. Nuevos registros de triatomíneos domiciliarios y extradomiciliarios en Colombia. Colombia Médica 12: 75-85.

Dujardin J P, Muñoz M, Chavez T, Ponce C, Moreno J, Schofield CJ 1997.The origin of Rhodnius prolixus in Central America. Med Vet Entomol 22: 101-103.

Guhl F, Schofield C J 1996. Population genetics and control of triatominae. Parasitol Today 12:169-170.

Guhl F, García M, Ching R, Juliao O, Jaramillo C, Pachón D, Molina S, Barrios D 1995. Enfermedad de Chagas Transfusional en Colombia. Tribuna Médica 91: 129136.

Marinkelle C J 1975. Epidemiology of Chagas disease in Colombia, p. 340-347. American Trypanosomiasis Research, Scientific Publication No. 318 PAHO/ WHO, Washington.

Vallejo GA, Silva JC, Castañeda N, Jaramillo JC, Carranza JC, Sánchez JL, Guhl F 1997. Two major sub-populations of Trypanosoma rangeli in Colombia defined by subspecific kDNA probes. Mem Ins Oswaldo Cruz 92: 192.

World Health Organization 1991. Control of Chagas Disease. Report of a WHO Expert Committee, WHO Technical Report Series 811, Geneva, 95 pp.

Zingales B, Souto RP, Mangia RH, Lisboa CV, Campbell DA, Jansen A, Fernandes O 1998. Molecular epidemiology of American trypanosomiais in Brazil based on dimorphisms of rRNA and mini-exon gene sequences. Interl J Parasitol 28:105-112. 